\title{
Storage Stability of Artificial Dry Fish Bait
}

\author{
K. Masilan ${ }^{\text {** }}$, N. Neethiselvan ${ }^{2}$, Lidiya Wilwet $^{3}$, R. Jeya shakila ${ }^{3}$ and K. Vijay ${ }^{1}$ \\ ${ }^{1}$ Department of Fish Processing Technology, ${ }^{2}$ Centre for Fisheries Technology, Training and \\ Incubation, ${ }^{3}$ Department of Fish Quality Assurance and Management, Fisheries College and \\ Research Institute, Tamil Nadu Fisheries University, \\ Thoothukudi - 628008, Tamil Nadu, India \\ *Corresponding author
}

\begin{tabular}{l}
\hline K e y w o r d s \\
$\begin{array}{l}\text { Fish waste utilization, } \\
\text { Red meat of tuna, } \\
\text { Artificial dry fish bait, } \\
\text { Fungal growth, Storage } \\
\text { study }\end{array}$ \\
\hline Article Info \\
\hline $\begin{array}{l}\text { Accepted: } \\
10 \text { April } 2018 \\
\text { Available Online: } \\
10 \text { May } 2018\end{array}$ \\
\hline
\end{tabular}

A B S T R A C T

Processing of seafood generates a huge quantity of wastes that are often diverted to fish meal production. Long line and trap fishing require live bait everyday to capture fishes. Small squids, sardines and trash fishes are generally used as live baits. Availability of live baits during all seasons and even the cost factor hinder the fishing quite often. As an alternative, development of "artificial dry bait" is gaining importance in recent years. In this study, artificial dry baits are prepared using tuna red meat discarded as waste by the tuna processing plant along with a suitable natural binder by single screw extrusion. The stability of the artificial bait in seawater was studied examine suitability as a bait. In order to enhance their storage quality and safety, baits are prepared with the addition of permitted antifungal agent, sodium benzoate at three different concentrations viz $0.1 \%$, $0.5 \%$ and $1 \%$, and subsequently packed in three ways viz. cloth bag, polyethylene bag and in open condition, prior to storage. The result indicated that the type of packaging influenced the growth of fungi. The bait held in open condition had higher fungal counts than those packed in cloth bags and polyethylene bags. Addition of antifungal agent had significantly reduced the fungal growth. The bait treated with $0.1 \%$ sodium benzoate had much lower counts, but those treated with $0.5 \%$ did not show any fungal growth. The fungal species identified mainly belonged to the genera, Candida and Aspergillus, besides a yeast, Torula. Torula was dominant in control bait, while Candida $s p$ was the major genera in $0.1 \%$ sodium benzoate treated bait. This study helped as to prepare a dry artificial bait by utilizing tuna red meat waste that can be held safe at room temperature without any quality defect.

\section{Introduction}

Trap fishing is one of the important fishing technique around the world, in which, bait plays a key role and decides the success (Lokkeborg et al., 1990). Forage fishes such as mackeral, herring, sardine, squids and anchovies are generally used as natural baits in traps and long lines. However, these fishes have good market demand as human food owing to their nutritional value. Because of the increased market demand, both for human 
food as well as for bait, the prices of these fishes have increased dramatically in the past decade. Hence in recent years, there have been efforts to produce artificial baits, which can substitute or rather more effective than natural fish baits for catching fish and other aquatic animals. Artificial lures resembling insects, small fishes, shrimps and other natural prey of fish species are widely used to catch certain fishes by visual stimulation around the world (Bjordal and Lokkeborg, 1996). However, such lures otherwise called jigs have potential use in capturing active predators in trolling lines. In general, traps and stationary hook and line fishing gears require baits that resemble natural baits with adequate attractants being released in a sustained manner till the capture of the fish. Attractants meant for the preparation of artificial fish baits should be cheap and at the same time, available year round and in large scale.

During processing, fish fillets account for 30 to $40 \%$ and rest of the $60-70 \%$, consisting head, guts, skin and fins are usually discarded as wastes. In some instances, these wastes are disposed away from the processing plant at no cost, just to avoid the accumulation of garbage in the processing site. Due to high organic content, fish waste is often classified as a certified waste, which requires early disposal from the vicinity of fish processing factories. This practice is coming under increased scrutiny due to environmental issues and is becoming an increasing concern and cost burden for the whole seafood industry. So, the protein rich wastes from fish processing factories can be used to manufacture fish protein concentrate, fish oils and useful enzymes such as pepsin and chymotrypsin, besides other value-added fishery products.

Among the various fish processing wastes, Tuna Red Meat (TRM) is notable as they are generated and processed year round. The landings of tuna from Indian seas during year
2015 have been estimated as 78,470 tonnes and Tamilnadu alone has contributed to a tuna catch of 15,885 tonnes, which accounts $20 \%$ of national tuna catch ( MPEDA, 2016). Moreover,TRM constitutes about $11 \%$ of the total body weight of tuna and it is a good source of essential amino acid and iron content ( George, 1993; Thankappan et al., 1995). Conversion of red meat as fish meal requires a huge capital investment and hence formulation of aquaculture feed is yet another option available (Faid et al., 1997).

Need for the hygienic condition of bait without notable microbial load has been stressed by researchers as the bait consumed by the fishes is to be used for human consumption.

Chanes-Miranda and Viana (2000) inferred that the baits meant for the capture of lobster should be hygienic with low microbial load as the lobsters caught with baits are used as human food.

In the present study, was planned to develop artificial fish baits with antifungal agent suitable for use in fish traps using fish processing and poultry wastes.

\section{Materials and Methods}

\section{Experimental design}

Boiled poultry intestinal muscles and Tuna Red Meat (TRM) from yellow fin tuna, Thunnus albacore. Further, Tapioca Flour (TF) which is commonly used in fish feed preparation and Kadukkai powder (seed powder of Termineliachebula) (KP) which is used as an important herbal medicine for human being (Gupta, 2012; Velayudam et al., 2012) and has been used as binder in ancient civil construction ( Emayan and Rahuman, 2015) were used as binders for the preparation of artificial dry baits in the present study. 


\section{Standardization of concentration of antifungal agent}

The successfully evolved bait was prepared incorporating the antifungal agent, sodium benzoate $(\mathrm{NaB})$ as used by Chanes-Miranda and Viana (2000) in artificial dry fish bait at four different levels such as $0 \%, 0.1 \%, 0.5 \%$, and $1 \%$ by suitably reducing the quantity of TRM and Poultry wastes in the respective baits.

\section{Standardization of packaging material}

The TRM based baits prepared in four different concentrations such as $0 \%, 0.1 \%$, $0.5 \%$ and $1 \%$ were packed in three different packaging materials such as cloth bag, PE cover, open glass beaker. The first set of baits was packed in cloth bags having the dimension of $17 \mathrm{~cm}$ long and $13 \mathrm{~cm}$ broad. The second set of baits was packed in PE covers with the dimension of 7-inch-long and 10 inch broad. The third sets of baits were kept in $250 \mathrm{ml}$ glass beakers in open condition. Samples were drawn from each of the three sets at an interval of one month up to 6 months for analyzing total fungal count (TFC) following the method of APHA (1992).

\section{Results and Discussion}

Fungi belonging to the genera Candida spp and Aspergillus spp were observed during storage of the bait with different concentration of NaB. Apart from the fungi, the yeasts belonging to the genus Torula were also observed.

Non availability of fungal infections in this bait such as $0.5 \%$ and $1 \%$ was noticed when packed in PE bag (Fig. 1) and raising the level of $\mathrm{NaB}$ to $1 \%$ could delay the onset of fungal infection by one month and four months, when kept in open condition and packed in cloth bags respectively. Hence, it is clear that addition of $0.5 \% \mathrm{NaB}$ in artificial dry bait and packaging in closed PE bag could extend the shelf life of the bait up to six months without any fungal attack. Addition of further, Sodium benzoate at $1 \%$ level and package in PE bags could also completely arrest the fugal growth (Fig. 1). However, $0.5 \%$ level of $\mathrm{NaB}$ was found to be the optimal dose for artificial dry baits when packed in PE bag.

Water activity has been found to be a factor that decides the vulnerability of a food product to microbial growth Abdullah et al., (2000) recommended that the level of $a_{w}$ should exceed 0.65 in starch-based foods in order to avoid fungal growth up to 6 months of storage. However, in the present study even at the low $\mathrm{a}_{\mathrm{w}}$ level of $0.58 \pm 0.02$, fugal growth was observed in all the baits except the bait with the $\mathrm{NaB}$ concentration of $0.1 \%$ and $0.5 \%$ packed in PE bag. The reason may be attributed to high level of protein leaching of the bait 21a (51.92\%). This revealed the fact that the bait requires the inclusion of $\mathrm{NaB}$ at $0.1 \%$ level and packing in PE bag to avoid fugal growth up to 6 months.

Packing bait in PE bag without addition of antifungal agent could prolong the storage period of bait up to two months however, fungal infection started two month onwards. The addition of $\mathrm{NaB}$ at $0.1 \%$ level did not show any visible impact on the fungal growth in relation to control bait. The onset of fungal infection started after two months both in the baits (Fig. 2).

Rising of level of $\mathrm{NaB}$ could delay the onset of fungal infection by one month and four months when kept in open condition and packed in cloth bags respectively. Hence, it is clear that addition of $1 \% \mathrm{NaB}$ and packaging in closed PE bag could extend the shelf life of the bait up to six months without any fungal infestation. 
Fig.1 Changes in total fungal count of the artificial dry bait with different concentrations of $\mathrm{NaB}$ and stored under different packaging conditions
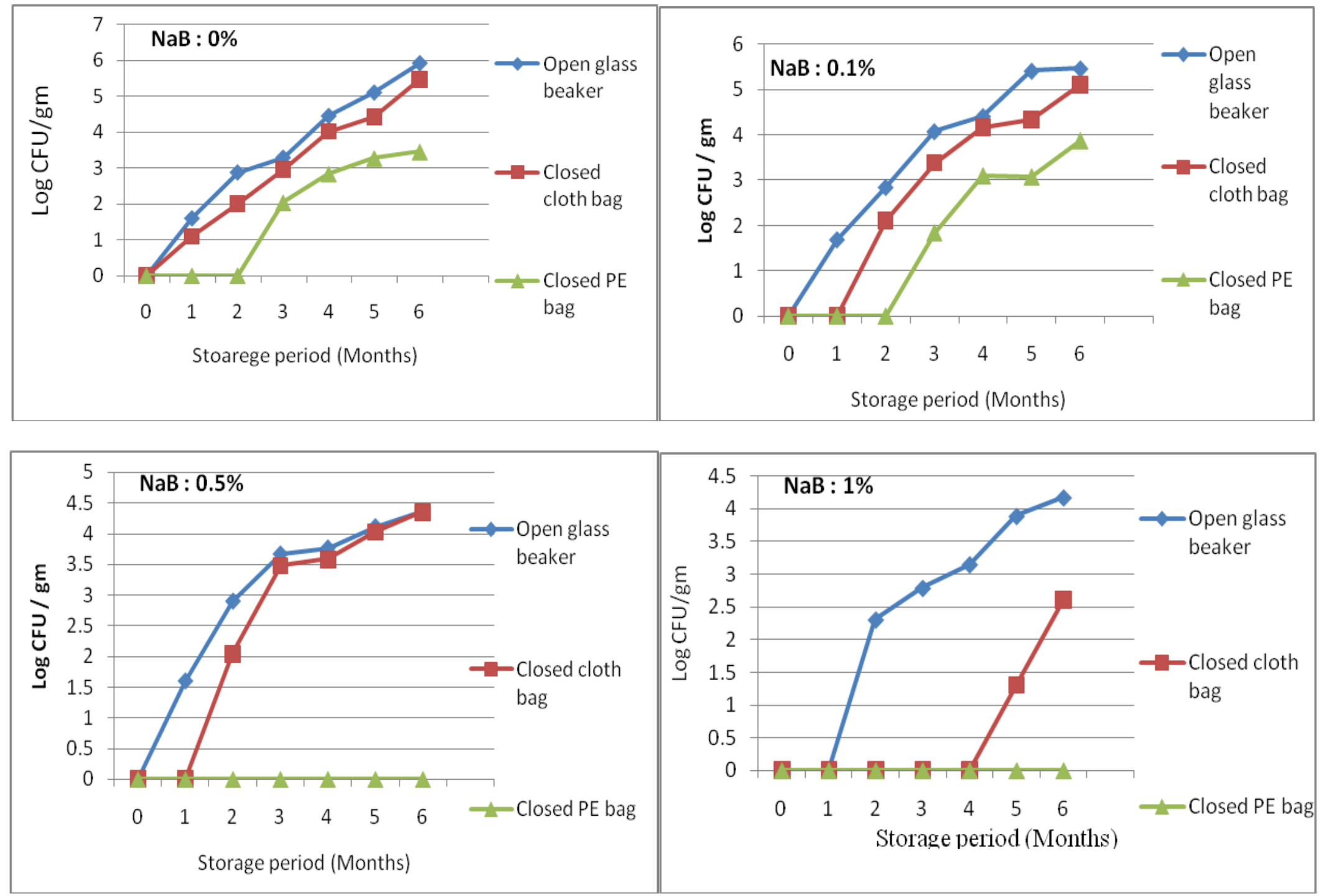
Fig.2 Changes in total fungal count of the artificial bait with different concentrations of $\mathrm{NaB}$ and stored under different packaging conditions

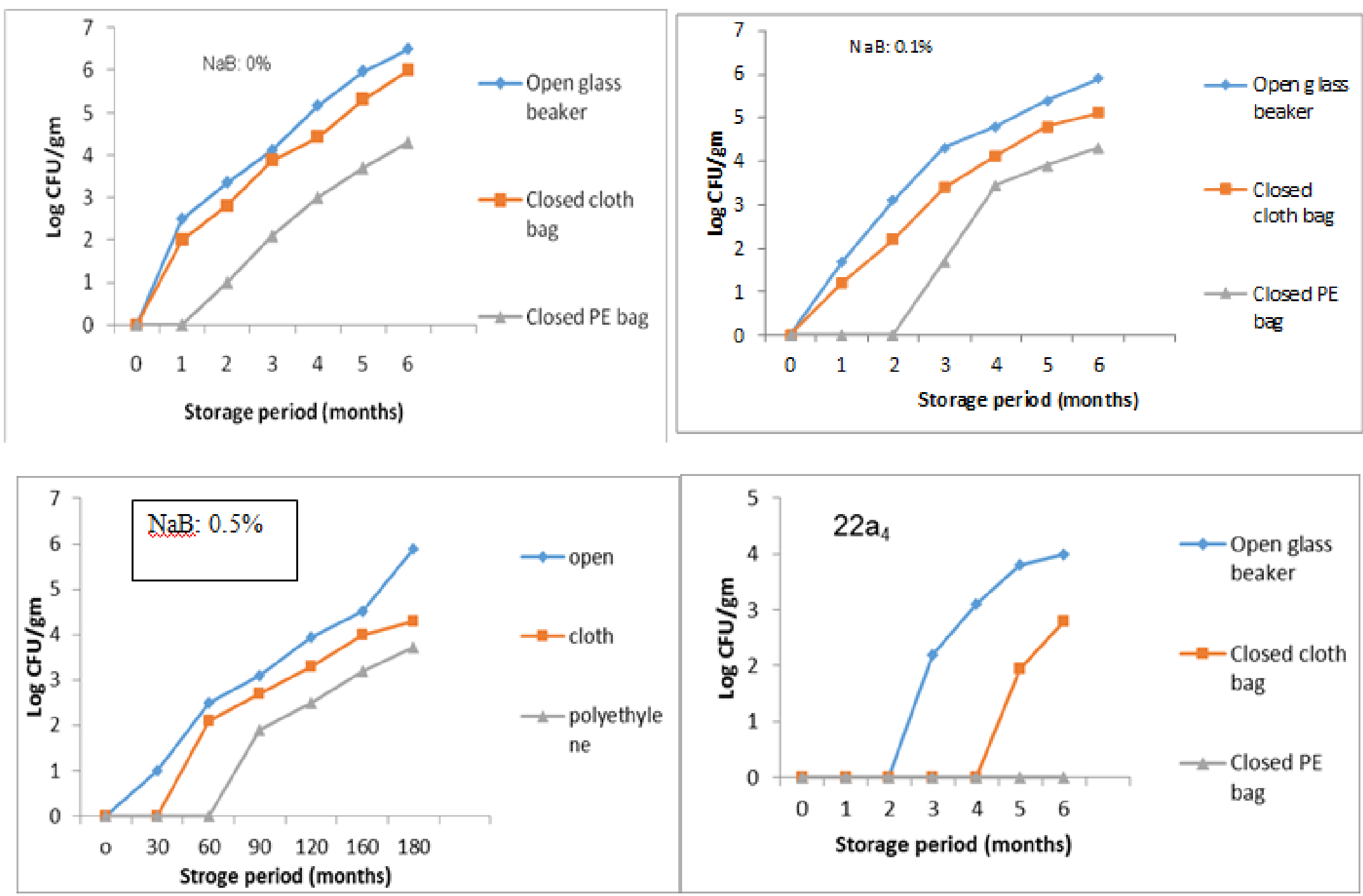


Fugal growth was observed in all the baits except the bait with the $\mathrm{NaB}$ concentration of 1\%packed in PE bag (Fig. 2). This revealed the fact that the bait requires the inclusion of $\mathrm{NaB}$ at $1 \%$ level and packing in PE bag to avoid fugal growth up to 6 months (Fig. 2).

Availability of live baits during all seasons and even the cost factor hinder the fishing quite often. As an alternative, development of "artificial dry bait" is gaining importance in recent years. In this study, artificial dry baits Incorporating $0.5 \%$ of $\mathrm{NaB}$ in the newly evolved artificial dry bait and packing it in PE cover could extend the shelf life up to 6 months without any fungal attack. This study helped as to prepare dry artificial bait by utilizing tuna red meat waste that can be held safe at room temperature without any quality defect.

\section{References}

Abdullah, N., Nawawi, A., Othman, I., 2000. Fungal spoilage of starch-based foods in relation to its water activity (aw). Journal of stored products Research, 36. 47-54.

APHA, 1992. Compendium of Methods for the Microbiological Examination of Foods, (Ed.) M.L. Speck, APHA Publication, Washington, USA.

Balachandran, K.K., Kandoran, M.K., Gopakumar, K., Nair, M.R., 1993 Processing and utilization of tuna. Proceedings of the national conference of tunas (Cochin)/ http://eprints.cmfri. org.in/5099/1/06.pdf / Accessed 26.4.2017

Chanes-Miranda, L., Viana, M.T., 2000. Development of artificial lobster baits using fish silage from tuna by-products. Journal of Shellfish Research, 19(1), 259-263.

Chichester, D.F., Tanner, R.W., 1972. Antimicrobial food additives. In
Handbook of Food Additives, (T.E. Furia, ed.) pp.115-184, CRC Press, Cleveland, Ohio.

CMFRI (Central Marine Fisheries Research Institute in India). CMFRI annual report 2015-2016. ( 2015). http://eprints.cmfri. org.in/10897/1/CMFRI\%20ANNUAL\% 20REPORT\%202015-16.pdf /Accessed 15.4.2017

Emayan, R., Rahuman, S.A., 2015. Study on the compressive strength of lime mortar using admixtures. International journal of innovative research in engineering \& management. 3(1), 201-203.

Faid. M., Zouiten. A., Elmarrakchi. A., Begdouri.

A.A., 1997.

Biotransformation of fish waste into a stable feed Ingredient. Food Chemistry, Vol 60, No 1, 13-18.

George, C., 1993. Biochemical differences between the red and white meat of tuna and changes in quality during freezing and storage. Fishery Technology. 12, 70-74.

Lokkeberg, S., Siikavuopio, S.I., Humborstad, O., Utne-Palm, A, C., Ferter. K., 2014. Towards more efficient long line fisheries: fish feeding behavior, bait characteristics and development of alternative baits, Rev Fish Biol Fisheries, 24, 985-1003.

MPEDA (Marine Product Export Development Authority India). Culture fisheries production. (2015). State-wise details of Shrimp and Scampi Production. http://mpeda.gov.in/ MPE DA/cms.php?id=eWVhci13aXNlL XNwZWNpZXMtd21zZS1zdGF0ZS13 aXNl\#/Accessed 18.4.2017

MPEDA (Marine Product Export Development Authority India). Press Release Export statistics, (2015). http://mpeda.gov.in/MPEDA/pdf/press_ release/MPEDA_Press_Release_Export _statistics_2014_15_and_RGCA_2.pdf/ Accessed 18.04.2017 
Thankappan, T.K., George, C., Nair, K.G.R., 1995. Utilization of tuna and tuna waste. National symposium on technological advancements in fisheries and its impact on rural development, Cochin, 329-333.

\section{How to cite this article:}

Masilan, K., N. Neethiselvan, Lidiya Wilwet, R. Jeya shakila and Vijay, K. 2018. Storage Stability of Artificial Dry Fish Bait. Int.J.Curr.Microbiol.App.Sci. 7(05): 1177-1183.

doi: https://doi.org/10.20546/ijcmas.2018.705.143 